\title{
PRÁXIS E "CATARSIS" COMO REFERÊNCIAS AVALIATIVAS DAS AÇÕES EDUCACIONAIS DAS ONG'S, DOS SINDICATOS E DOS PARTIDOS POLITICOS
}

\author{
Marcos Francisco Martins*
}

Recebido: 23 nov. 2010

Aprovado: 20 dez. 2010

* Professor Adjunto da UFSCar-campus Sorocaba e bolsista de produtividade em pesquisa do CNPq. É
licenciado em Filosofia, com Mestrado e Doutorado em Filosofia e História da Educação, Sorocaba - SP
- Brasil. E-mail: marcosfmartins@ufscar.br

Resumo: O presente artigo trata das referências avaliativas das ações educacionais desenvolvidas pelas ONG's, sindicatos e partidos políticos, que são entendidas como práxis capazes de gerar "catarsis" de diferentes tipos. Sustentado teoricamente em, basicamente, três autores: Marx, Gramsci e Vázquez, o texto inicia apresentando alguns apontamentos sobre o conceito de práxis e sobre o de "catarsis", para posteriormente identificar a educação como um processo práxico e catártico. Essa compreensão da educação, que resgata os conceitos de "práxis comunitária" e "práxis social", resulta em dupla asserção conclusiva, a saber: primeiro, que todo processo educativo resulta em alguma transformação e, segundo, que nem toda transformação resultante da educação é capaz de alterar as estruturas e superestruturas que caracterizam a totalidade da vida social.

Palavras-chave: Antônio Gramsci (1891-1937). Avaliação. Catarse. Educação. Práxis.

\section{PRAXIS AND “CATARSIS” AS EVALUATIVE REFERENCES OF THE \\ EDUCATION ACTIVITIES OF NGO’S, TRADE UNIONS AND POLITICAL PARTIES}

Abstract: This article refers to the evaluation of educational activities developed by NGO's, trade unions and political parties, which are understood as praxis capable of generating "catharsis" of different types. Referenced in basically three authors: Marx, Gramsci and Vázquez, the text begins by presenting some remarks on the concept of praxis and "catharsis", identifying afterwards education as a process at the same praxic and cathartic. This understanding of education, which recalls the concepts of "community praxis" and "social praxis", resulting in a double conclusive assertion, namely: first that the entire educational process results in some change, and second, that not all resulting transformation of education is able to change the structures and superstructures that characterize all social life.

Key words: Antonio Gramsci (1891-1937). Evaluation. Catharsis. Education. Praxis.

\section{INTRODUÇÃO}

O presente texto foi elaborado com vistas a delinear alguns parâmetros para avaliar ações educacionais não escolares, especificamente as efetivadas pelas ONG's, pelos sindicatos e pelos partidos políticos. Pode, portanto, servir aos propósitos dos pesquisadores, estudiosos e educadores que se interessam por ajuizar processos educacionais que se efetivam fora do ambiente escolar. 
Todavia, em particular, ressalte-se que este artigo insere-se na dinâmica de execução projeto de pesquisa intitulado Fundamentos, perspectivas e métodos das iniciativas educacionais não-escolares desenvolvidas na Região Metropolitana de Campinas por partidos políticos, sindicatos e ONG's, que em 2009 foi aprovado pelo Programa de Bolsa de Produtividade em Pesquisa - PQ - do CNPq (Conselho Nacional de Desenvolvimento Científico e Tecnológico) e em 2011 encontra-se em fase de consecução. Com esse objetivo específico, este texto configura-se também como uma orientação à avaliação que se fará das ações educativas desenvolvidas por uma amostra de organizações sociais não escolares que atuam Região Metropolitana de Campinas-SP, composta por dezenove cidades.

Ao avaliar as ações educacionais das ONG's, sindicatos e partidos políticos pode-se tomar como objeto suas mais diferentes dimensões. Mas, como o entendimento é o de que tais ações teórico-práticas voltadas ao desenvolvimento de processos de ensino-aprendizagem são práxis que resultam em "catarsis" de variados perfis, resolveu-se resgatar o conceito marxiano de práxis, na primeira parte deste artigo, e a concepção gramsciana de "catarsis", na segunda parte, de maneira a, posteriormente, identificar a educação como um processo práxico que pode ser também produtor de "catarsis".

Assim estruturado, o texto segue, nas linhas conclusivas, com apontamentos sobre as possibilidades que se tem de, fundamentando-se em Vázquez, qualificar as práxis educativas (que variam de acordo com o grau de consciência do sujeito e com os resultados alcançados com a ação) e também, tendo como referência o pensamento gramsciano, o tipo de "catarsis" que elas provocam nos indivíduos e nos grupos sociais, isto é, os impactos nas consciências e na decorrente ação que efetivam na realidade sócio-histórica.

Com o intuito de identificar as práxis educativas desenvolvidas pelas ONG's, sindicatos e partidos políticos, a partir da concepção que o paradigma teórico-metodológico gramsciano tem de práxis e de "catarsis", o texto resgata os conceitos anteriormente desenvolvidos de "práxis comunitária", aquela cujo impacto transformador limita-se ao sujeito e ao seu micro-cosmo vivido, e de "práxis social", que é justamente a práxis cujo impacto transformador é mais amplo, repercutindo para além do sujeito individual e de seu ambiente próximo, comunitário, atingindo as estruturas e as superestruturas de uma determinada formação econômica e social. 


\section{APONTAMENTOS SOBRE O CONCEITO DE PRÁXIS}

Muito embora algumas línguas, com suas particularidades sócio-culturais e históricas, não distingam prática de práxis, é preciso considerar que há entre esses termos diferenças importantes.

A primeira dessas distinções pode ser identificada pelo uso que se faz dos termos prática e práxis. A palavra prática é de uso corrente, tanto que a ela recorre rotineiramente o senso comum, sendo a práxis um termo cujo uso é mais restrito aos diálogos que se estabelecem em comunidades acadêmicas. Todavia, essa distinção não é a mais significativa.

Mais importante do que a diferenciação pelo uso corrente, os termos prática e práxis se diferem também por terem significados diversos. Muito embora indiquem algo relacionado ao empírico, ao concreto, portanto, ao prático, prática e práxis não são sinônimos, de maneira que não podem ser confundidas no que se refere aos seus significados, e uma forma de demonstrar isso é recorrer à história.

Para os gregos antigos, de onde advém o termo práxis, esta palavra, principalmente para Aristóteles, designava a ação de um sujeito que não produz nada fora de si mesmo, como é o caso, por exemplo, da moral (referências normativas ao indivíduo, que podem ser forjadas segundo a razão e, assim, seguidas como uma prática habitual do homem virtuoso para que alcance a felicidade) e mesmo da política, cujo objetivo fundamental é o de promover, por meio do Estado, a moral junto à coletividade de cidadãos, a pólis, de forma a que alcance o bem comum. As ações cujo resultado produz algo fora do agente eram identificadas por Aristóteles pelo termo poíesis; esse é o caso do trabalho de um artesão, que produz, por exemplo, uma mesa, algo que lhe é completamente exterior. ${ }^{1}$ Considere-se, aqui, também que, "Além disso, em certas passagens, Aristóteles parece identificar praxis com a eupraxia (boa práxis), por oposição à dyspraxia (má práxis, infelicidade)" (BOTTOMORE, 1988, p. 292).

Há, portanto, segundo Aristóteles, clara distinção entre fazer (ou produzir) e agir, e cada qual demanda um tipo específico de conhecimento: o conhecimento da produção e o conhecimento da ação. Além desses tipos específicos de conhecimento, Aristóteles reconhecia também outros, como é o caso do esforço humano para conhecer a verdade, sem finalidade prática imediata.

1 “A distinção entre 'ação' (práxis) e 'produção' (poiesis) é dada por Aristóteles quase sempre por evidente, e consiste no fato de que a ação não produz nenhum objeto diferente dela mesma, isto é, termina em si, enquanto a produção dá lugar a um objeto diferente de si, que é o produto.” (BERTI, 1998, p. 157). 
Hoje, entretanto, essas palavras praxis e poíesis perderam, em grande medida, o sentido originário ${ }^{2}$. E muitas vezes se observa o uso empobrecido de tais termos (ação e produção) porquanto são mediados pela noção positivista, que os reduzem à simples técnica, orientando-os no processo de compreensão e execução por uma pseudoconcreticidade ${ }^{3}$.

Contudo, se contemporaneamente a concepção aristotélica do termo práxis foi modificada, muitas vezes empobrecendo-a, há também autores responsáveis pelo resgate enriquecedor e superador do conceito originário. Um dos autores a fazer isto, por exemplo, foi Marx. Ele concebe a práxis como um processo teórico-prático por meio do qual o homem torna-se capaz de superar a especulação (assim concebida a práxis, ela é uma crítica à filosofia) e efetivar no mundo projetos conscientes, do que resulta ser ela também uma ação. Esse entendimento de práxis sustenta-se no postulado fundante tanto da concepção dialética de mundo (ontologia) da teoria marxiana, quanto de sua epistemologia, ou melhor, do princípio explicativo que utiliza para orientar o processo de conhecimento da realidade, e também de sua axiologia (teoria da ação) e antropologia (noção de homem), qual seja o de que a realidade é uma totalidade que, movida por contradições, expressa a síntese entre ser e pensar, objetivo e subjetivo, sujeito e objeto, estrutura e superestrutura. Isso fica evidente na II Tese sobre Feuerbach, que projeta epistemológica e axiologicamente o materialismo histórico e dialético ao entendimento de que a verdade não é uma questão eminentemente teórica, mas prática, sendo, portanto, a práxis o seu critério de validade do conhecimento: "A questão de saber se ao pensamento humano pertence a verdade objetiva - não é uma questão teórica, mas uma questão prática. É na práxis que o homem tem de comprovar a verdade, isto é, a realidade e o poder, o caráter terreno, do seu pensamento." (MARX, 1984, p. 107-108 - grifo do autor). Assim entendida por Marx, a práxis tem primazia em relação à teoria na superação das contradições e dos problemas que a vida social e os sistemas de sua produção e reprodução apresentam ao homem, uma compreensão da qual resultou sua famosa crítica à filosofia vigente até então, expressa na XI Tese: "Os filósofos têm apenas interpretado o mundo de maneiras diferentes, a questão é transformá-lo.” (MARX, 1984, p. 111 - grifos do autor).

Esse posicionamento marxiano em favor da práxis é tão decisivo que Gramsci, inspirado principalmente por Labriola, identificou o materialismo histórico e dialético como "filosofia da práxis". E isso pelo fato de que, segundo Gra-

2 Veja-se o caso do termo poiésis, por exemplo, do qual derivaram as palavras poesia e poeta, que atualmente pouca relação têm com a matriz grega.

3 "A pseudoconcreticidade é justamente a existência autônoma dos produtos do homem e a redução do homem ao nível da praxis utilitária." (KOSIK, 1976, p. 19 - grifos os autos). 
PRÁXIS E "CATARSIS" COMO REFERÊNCIAS AVALIATIVAS DAS AÇÕES EDUCACIONAIS DAS ONG'S, DOS SINDICATOS E DOS PARTIDOS POLIITICOS

msci, o marxismo tem como uma de suas características "[...] negar a 'filosofia absoluta' ou abstrata e especulativa" (GRAMSCI, 1995a, p. 266), porque os problemas filosóficos tornam-se concretos no terreno da história, que é seu nascedouro e ambiente em que se desenvolvem. Daí o entendimento de que, na relação entre teoria e prática, "A precedência passa à prática, à história real das modificações das relações sociais, das quais, portanto (e, em última análise, da economia), surgem (ou são apresentados) os problemas que o filósofo se propõe e elabora" (p. 266).

Seguindo a tradição marxiana forjada no século XIX e desenvolvendo-a na nova realidade do século XX, sem com ela promover rupturas, tanto sob o ponto de vista ontológico, quanto epistemológico, axiológico e antropológico (MARTINS, 2008), Gramsci entendeu a práxis como um conceito capaz de bem expressar a unidade fundamental que se estabelece na totalidade da vida social entre ser e pensar, "[...] aliás, é imprescindível - fixar e recordar que realidade em movimento e conceito da realidade, se podem ser logicamente distinguidos, devem ser concebidos historicamente como unidade inseparável" (GRAMSCI, 1995a, p. 247). Ou seja, "Para a filosofia da praxis, o ser não pode ser separado do pensar, o homem da natureza, a atividade da matéria, o sujeito do objeto; se se faz esta separação, cai-se em uma das muitas formas de religião ou na abstração sem sentido" (GRAMSCI, 1995a, p. 70 - grifo do autor). E isso porque “[...] não é verdade que a filosofia da praxis 'destaque' a estrutura das supra-estruturas; ao contrário, ela concebe o desenvolvimento delas como ìntimamente relacionado e necessariamente inter-relativo e recíproco." (p. 263 - grifo do autor).

Ao expor a concepção dialética que tem da realidade, Marx, em seus textos, parece, muitas vezes, confundir práxis e trabalho, utilizando-as como sinônimos. Contudo, em algumas passagens dos trabalhos da maturidade, fica evidente a distinção entre trabalho e práxis: “[...] todo trabalho é uma forma auto-alienada de atividade produtiva humana, e deveria ser 'abolido'. A forma não alienada da atividade humana, anteriormente chamada de práxis, passa a receber o nome de 'auto-atividade"' (BOTTOMORE, 1988, p. 294). Em O Capital, Marx refere-se ao trabalho como atividade auto-alienada, sobretudo em se tratando do trabalho efetivado na dinâmica de desenvolvimento do modo de produção capitalista, e neste sentido ele é alienado e alienante; em oposição a este processo, ele expressa seu projeto político de superar a realidade capitalista por outra em que a ação humana (práxis) seria livre, universal e criativa, e, portanto, não causaria estranhamento ao homem, promovendo sua auto-alienação, mas a própria auto-realização, uma condição que só pode ser alcançada pela práxis 
revolucionária ${ }^{4}$, que ao mesmo tempo cria (produz) e transforma (no sentido de superar, aperfeiçoando e reconfigurando) a realidade em uma realidade mais humana. Dessa forma, Marx funda um novo materialismo, que é histórico e dialético, e que, assim, concebe a totalidade das relações sociais como processo, superando a histórica dicotomia entre "[...] o materialismo e o idealismo [...] pela práxis revolucionária” (LEFEBVRE, 2002, p. 149).

Destaque-se que esse materialismo marxiano originário é resultado de uma profunda síntese resultante de três matrizes teóricas: “[...] a filosofia clássica alemã, a economia política clássica inglesa e o socialismo francês" (LÊNIN, 1985, p. 15). E é principalmente em Hegel e Fuerbach que Marx busca referências para produzir seu conceito de práxis. No Hegel de $A$ Filosofia do Direito e em Fenomenologia do Espírito encontram-se as pistas seguidas por Marx para construir seu conceito de práxis, que supera a noção hegeliana ${ }^{5}$, pois neste livro é possível identificar a ação humana como produtora histórica em seu conjunto, a partir da dialética relação entre o mundo das necessidades dos indivíduos e dos grupos sociais (sociedade civil), que o trabalho procura saciar, e todo o arcabouço jurídico-político estatal, que para Hegel "[...] consolida e complementa a sociedade" (LEFEBVRE, 2002, p. 147). De outro modo, em oposição ao idealismo hegeliano, apresentou-se o naturalismo antropológico de Feuerbach, que muito embora tenha destacado a importância da ação consciente do sujeito na constituição do mundo, carece de historicidade. E isso porque o autor de $A$ essência do cristianismo trata o homem como um ser abstrato, ou melhor, um ser destacado do mundo ao seu redor, que mantém com o homem uma relação passiva. Eis o que Marx critica, pois, para a concepção marxiana, sujeito e objeto formam uma totalidade interatuante, interdependente, intercomunicante, isto é, dialética, e é nessa dialeticidade que se produz a história ${ }^{6}$. Esta, portanto, não se restringe a um processo em que o espírito se materializa, produzindo cultura por meio do trabalho, para se auto-identificar, como em Hegel, e nem

4 "A coincidência da mudança das circunstâncias e da atividade humana ou autotransformação só pode ser tomada e racionalmente entendida como práxis revolucionária.” (MARX, 1984, p. 108 - grifos do autor).

5 "A noção de práxis se encontra já em Hegel e, ao mesmo tempo, não se encontra. Com efeito, no sistema filosófico-político de Hegel, o Estado providencial e divino propõe suas condições, que só têm importância e interesse como materiais de construção do edifício jurídico e político. Não vendo nesses elementos e condições senão "momentos" sem substância da própria realidade superior - o Estado - Hegel os despreza." (LEFEBVRE, 2002, p. 148-149).

6 "A insuficiência principal de todo materialismo até os nossos dias (o de Feuerbach incluído) é a de a coisa (Gegenstand), a realidade, o mundo sensível, serem tomados apenas sob a forma do objeto (Objekt) ou da contemplação (Anschauung); mas não como atividade humana sensível, práxis [...] Daí que na Essência do Cristianismo, apenas considere a atitude teórica como genuinamente humana, ao passo que a práxis é apenas tomada e fixada na sua forma de manifestação sordidamente judaica." (MARX; ENGELS, 1984, p. 107 - grifos dos autores). 
é uma realidade em si, passiva, e que, como tal, é objeto contemplado pelo homem que a produziu com sua atividade, não considerando a relação dialética entre sujeito e objeto, como em Feuerbach ${ }^{7}$. Para Marx, a história é síntese do movimento dialético gerado pelas contradições entre estrutura e superestrutura social: "A história pode ser considerada de dois lados, dividida em História da natureza e história dos homens. No entanto, estes dois aspectos não se podem separar; enquanto existirem homens, a história da natureza e a história dos homens condicionam-se mutuamente" (MARX, 1984, p. 11).

A dicotomia, portanto, entre materialismo, como o de Feuerbach, e idealismo, como o de Hegel, é superada em Marx pela noção que apresenta do termo práxis. Com efeito, na tradição marxista, a práxis tornou-se identificada como um processo superador dessas separações cabais entre sujeito e objeto, homem e natureza, objetivo e subjetivo, que são inexatas para identificar o que vem a ser a totalidade da vida social, que é, sobretudo, unidade, mas unidade na diversidade: "O concreto é concreto porque é a síntese de múltiplas determinações, isto é, unidade do diverso" (MARX, 1991, p. 16).

Vázquez trata dessa questão em seu texto intitulado A filosofia da práxis. Neste, entende a práxis como a "[...] atividade material do homem que transforma o mundo natural e social para fazer dêle um mundo mais humano" (VÁZQUEZ, 1977, p. 3). Assim, Vázquez parece identificar práxis com o trabalho, seguindo a acepção marxista deste conceito: trabalho é um processo imanente ao desenvolvimento histórico da humanidade por meio do qual o homem, em busca da sobrevivência, originariamente, e mais atualmente com vistas a garantir sua existência, transforma a natureza e, neste processo, transforma também a si mesmo, produzindo um mundo à sua imagem e semelhança ${ }^{8}$. Desse posicio-

7 Destaque-se que a influência de Feuerbach em Marx é compreendida das mais variadas formas por diferentes estudiosos do pensamento marxiano. Há, entre eles, desde os que entendem que todo o conceito de práxis em Marx já se encontrava completamente formulado em Feuerbach, como Mondolfo, até os que entendem que Marx inova sob esse ponto de vista, formulando um conceito original, como Vázquez. Uma discussão sobre essa questão vista por esses dois autores encontra-se no Capítulo I - O materialismo do marxismo originário - do livro Marx, Gramsci e o conhecimento: ruptura ou continuidade? (MARTINS, 2008).

8 "Antes de tudo, o trabalho é um processo do qual participam o homem e a natureza, processo em que o ser humano, com sua própria ação, impulsiona, regula e controla seu intercâmbio material com a natureza. Defronta-se com a natureza como uma de suas forças. Põe em movimento as forças naturais de seu corpo - braços, pernas, cabeça e mãos -, a fim de apropriar-se dos recursos da natureza, imprimindo-lhe forma útil à vida humana. Atuando assim sobre a natureza externa e modificando-a, ao mesmo tempo modifica sua própria natureza. Desenvolve as potencialidades nela adormecidas e submete ao seu domínio o jogo das forças naturais. [...] Pressupomos o trabalho sob a forma exclusivamente humana. Uma aranha executa operações semelhantes às do tecelão, e a abelha supera mais de um arquiteto ao construir sua colméia. Mas o que distingue o pior arquiteto da melhor abelha é que ele figura na mente sua construção antes de transformá-la em realidade. No fim do processo do trabalho aparece um resultado que já existia antes idealmente na imaginação do trabalhador" (MARX, 1999, p. 211-212). 
namento de Vázquez (p. 185) resulta que "Tôda praxis é uma atividade, mas nem toda atividade é uma praxis", distinguindo claramente práxis e prática.

Aceito esse conceito de práxis de Vázquez, é possível inferir dele que todo homem é, além de ser prático (leia-se: um ser que age mecanicamente, mimeticamente e, por vezes, também motivado por impulsos instintivos ou padronizados socialmente), um ser também práxico, pois age, ou melhor, trabalha, com vistas a garantir a sua existência (o que exige certa atividade consciente que, em muitos casos, pode ser racional e reflexivamente efetivada; leia-se: contrária aos instintos e padrões sociais) e essa sua ação repercute no mundo natural e social, incluindo aqui as decorrências da ação no plano subjetivo e intersubjetivo dos indivíduos e grupos sociais.

Segundo Vázquez, a práxis pode ser exercida de diferentes maneiras, que variam em relação ao grau de consciência que se tem da ação e ao resultado por ela obtido.

Tendo como referência o grau de consciência que o sujeito tem da práxis, Vázquez faz a seguinte distinção entre elas:

a) a práxis criativa: consiste na ação livre, criativa e criadora, que se apresenta diferente do padrão moral, político e legal vigentes, sendo, portanto, o seu maior exemplo, a ação revolucionária, pois produz algo radicalmente novo;

b) práxis reiterativa ou repetitiva: é ação que repete gestos mecanicamente consolidados, como a que é exercida pelo burocratismo de Estado, que também guarda possibilidades de criar;

c) práxis mimética: ação que segue um modelo pré-determinado, que pode ser vista como uma variação da práxis reiterativa ${ }^{9}$, e que pode criar, mas sem saber ao certo por que e como.

Além desses tipos, Vázquez também apresenta a anti-práxis, que é aquela ação pela qual o sujeito, conscientemente, visa a destruir a práxis criativa (VÁZQUEZ, 1977, p. 376).

Sob o ponto de vista do resultado alcançado, a práxis, segundo Vázquez, pode ser, basicamente, de dois tipos:

a) reflexiva: assim identificada quando o resultado alcançado pela práxis está de acordo com o que foi conscientemente estabelecido, racionalmente planejado, almejado, projetado;

9 Essa diferenciação entre os tipos de práxis é feita também por Lefebvre, que julga ser “[...] fiel à inspiração de Marx" (LEFEBVRE, 2002, p. 157). 
b) espontânea: é aquela práxis cujo resultado obtido não foi mediado pela reflexão racional do sujeito que a efetivou.

Muito embora essa tipificação seja útil, em muitos casos, para identificar as ações na totalidade social, as ações dos sujeitos não se apresentam de forma tão clara e distinta, o que demanda do observador e principalmente do pesquisador social uma astúcia heurística, uma argúcia no trabalho de identificação da ação que está pretendendo conhecer. Por outro lado, a concepção que Vázquez tem de práxis é interessante porque, se bem observada, comporta elementos objetivos e subjetivos, interesses individuais e coletivos (leia-se: de classe), orientações epistemológicas e políticas para se entender, criticar e formular alternativas ao desenvolvimento histórico humano, superando, em larga medida, a simplista e rebaixada definição que se tem recorrentemente de práxis no ambiente acadêmico, como simples união entre teoria e prática, o que pode dar a entender que estas são esferas separadas do ser social.

Assim sendo, o conceito de práxis exposto por Marx, Gramsci e Vázquez pode ser um referencial para avaliar as ações que se transcorrem na dinâmica societária vivida pelos indivíduos e grupos sociais, como é o caso da educação desenvolvida pelas ONG's, pelos sindicatos, pelos partidos políticos e mesmo pelos movimentos sociais. Estes, em sua práxis educativa, têm a possibilidade de criar, ou melhor, de produzir transformações na vida material (ser) e espiritual (pensar), mas isso demanda um trabalho de superação do nível de consciência que indivíduos, grupos sociais e organizações de diferentes tipos têm da própria ação, isto é, uma "catarsis".

\section{O SENTIDO ORIGINÁRIO E CONTEMPORÂNEO DE "CATARSIS"}

O termo "catarsis" foi empregado na tradição médica grega, sobretudo por Aristóteles. Significava purgação, purificação, isto é, o ato de liberar de determinada "coisa" o que a perturba, porque lhe é estranho à sua natureza. Assim entendido, tornou-se um conceito com aplicações no âmbito da medicina, da psicologia, da ética e da política, e "[...] para designar também um fenômeno estético, qual seja, uma espécie de libertação ou serenidade que a poesia e, em particular, o drama e a música provocam no homem" (ABBAGNANO, 2000, p. 120).

Nesta tradição grega, cabe mencionar a compreensão de Plotino, para quem o termo "catarsis" designava o processo por meio do qual a alma poderia se libertar das limitações do corpo, de seus sentidos, emoções, volições, que com- 
prometem a passividade contemplativa pretendida para a alma. Para superar o mal que reside na matéria, a alma, segundo Plotino, deve voltar-se a si mesma e, como fim último, dedicar-se à contemplação do "uno", capaz de provocar o "êxtase", entendido como superação de tudo o que é terreno, como é próprio, segundo o autor, dos homens divinos e dos deuses.

Tais conceitos implicam a interpretação do sentido originário grego de "catarsis" como sendo um processo mediado pela razão, e razão entendida no sentido que Aristóteles lhe conferiu: como sendo a essência característica do homem, que guarda a possibilidade de orientá-lo a uma vida virtuosa, isto é, uma vida racional que o leva ao seu fim supremo, que é a felicidade (eudaimonia) alcançada na medida em que o homem busca, com uma atividade voltada para o bem ${ }^{10}$, a verdade. Aristóteles identificava duas virtudes intelectuais: a razão (sophia) e a prudência (phronesis); esta entendida como sabedoria prática, isto é, um conhecimento (episteme, que é diferente de opinião: doxa) voltado à melhoria da ação humana e que é capaz de efetivar-se como um hábito racional (diferente do vício), com vistas a atingir a felicidade. De modo que a felicidade não se confunde, em Aristóteles, com gozo físico resultante dos prazeres do corpo, mas constitui-se como aperfeiçoamento racional do homem, que se materializa na ação como justo meio entre os excessos e as faltas (vícios da ação humana).

Contudo, contemporaneamente, o termo "catarsis" foi reinterpretado, legando para a atualidade um conceito deveras diferente de sua acepção grega original. Um dos autores que fazem esse trabalho de releitura do termo "catarsis" é Gramsci, que o interpreta no contexto das disputas entre forças sócio-políticas tendo em vista a conquista da hegemonia em uma determinada formação econômica e social.

Para Gramsci, o processo de constituição de uma formação econômica e social não se restringe aos movimentos que ocorrem no âmbito da estrutura social, pois estes dialeticamente relacionam-se com os movimentos que ocorrem também no ambiente superestrutural, na dimensão subjetiva e intersubjetiva, na cultura, na religião e na visão de mundo que se sedimentou como senso comum. De maneira que, a determinação de um tipo específico de formação econômica e social não é reflexo inerte das condições econômicas vividas, pois o que acontece no âmbito estrutural tensiona a formação de toda uma superestrutura, que por

10 Eis uma das significativas diferenças entre Aristóteles e Platão. Para este, a idéia de bem é inata no homem, enquanto que para aquele ela é fruto de um exercício prático e intelectual (parte-se da sensação para alcançar a intelecção), do que decorre ser o mundo sensível algo realmente existente, cuja essência é o movimento constante (devir), e não mera ilusão ou cópia imperfeita do mundo das idéias. 
sua vez retroalimenta a estrutura ${ }^{11}$, seja reproduzindo-a, seja questionando-a, isto é, mostrando suas contradições, seus problemas, bem como os caminhos para superá-los. Gramsci destacou com muita propriedade, ou melhor, sem se deixar levar pelo idealismo, de um lado, ou pelo mecanicismo materialista, de outro, que o desenvolvimento das forças produtivas observado no período compreendido entre o final do século XIX e a primeira metade do XX revelou, com muita clareza, a importância da superestrutura na disputa pela hegemonia e, portanto, na determinação do tipo de vida social, sem desconsiderar o peso que a estrutura exerce neste processo. E é por isso que sua concepção é eminentemente dialética.

Assim entendida a relação entre estrutura e superestrutura, isto é, dialeticamente, Gramsci avalia os reflexos da disputa pela hegemonia que se estabelece na vida concreta entre os que dominam economicamente e dirigem ética e politicamente a vida social (a classe dominante: a burguesia, que é, ao mesmo tempo, detentora dos meios de produção, se apresenta como referência cultural e moral ao comportamento individual e coletivo, e se apropria do poder político) e os que são dominados e dirigidos (as classes subalternas, formada por indivíduos e grupos sociais do campo e da cidade, que se caracterizam como classe por serem portador da força de trabalho necessária ao processo de reprodução do capital e das relações sociais por ele configuradas). Tal processo é visto por Gramsci como comportando diferentes e articuladas dimensões, e uma delas se refere à consciência que os indivíduos e grupos sociais adquirem na dinâmica que constitui e desenvolve a vida de uma determinada formação econômica e social. Gramsci utiliza o termo "catarsis" para expressar a visão que tem deste problema e, assim procedendo, sugere caminhos a serem seguidos para que as classes subalternas possam agir para se tornarem hegemônicas, construindo uma realidade que atenda às suas necessidades e interesses, e não aos da classe dominante e dirigente. Diz Gramsci (1995a, p. 53):

Pode-se empregar a expressão "catarsis" para indicar a passagem do momento puramente econômico (egoísta-passional) ao momento ético-político, isto é, a elaboração superior da estrutura em superestrutura na consciência dos homens. Isto significa, também, a passagem do 'objetivo ao subjetivo' e da necessidade à liberdade. A estrutura da força exterior que subjuga o homem, assimilando-o e o tornando passivo, transforma em meio de liberdade, em instrumento para criar

11 “A estrutura e as superestruturas formam um 'bloco histórico', isto é, o conjunto complexo - contraditório e discordante - das superestruturas é o reflexo do conjunto das relações sociais de produção" (GRAMSCI, 1995a, p. 52). Para aprofundar o conhecimento sobre o conceito de bloco histórico em Gramsci e Portelli (1990). 
uma nova forma ético-política, em fonte de novas iniciativas. A fixação do momento "catártico" torna-se assim, creio, o ponto de partida de toda filosofia da praxis, o processo catártico coincide com a cadeia de sínteses que resultam do desenvolvimento dialético.

Ao imprimir esse sentido ao termo "catarsis", Gramsci chama a atenção para o fato de que o materialismo histórico e dialético (sinônimo de filosofia da práxis nos escritos gramscianos) não deve reduzir-se a uma teoria da estrutura, pois todo o processo de revolução social por ele pretendido passa também pela auto-representação que as classes têm de si mesmas, adquiridas no processo de disputa pela hegemonia. Além disso, está ele a criticar os que acreditavam - incluindo aí integrantes das fileiras marxistas - que a revolução socialista poderia ocorrer de cima para baixo, como em uma "revolução passiva", tal qual ocorreu com o Risorgimento (GRAMSCI, 1980, p. 75-81), desconsiderando o necessário envolvimento dos indivíduos das classes subalternas no processo de sua formulação e efetivação. Pelo contrário, a revolução socialista pretendida por Gramsci era por ele entendida como um processo complexo, que deveria necessariamente passar também pela elevação das consciências dos indivíduos das classes subalternas, de forma a que pudessem superar a condição de indivíduos submissos e indiferentes para projetarem-se na luta econômica e política como classe e, assim, adquirindo cada vez mais consciência de si e do mundo ao seu redor - leia-se: consciência de classe -, o que lhes possibilitaria romper com a passividade política e empreender novas ações tendo em vista a transformação radical das relações sociais capitalistas.

Com efeito, com a elevação da consciência e, ao mesmo tempo, com a maior projeção das classes subalternas na disputa pela hegemonia, elas poderiam superar a condição de dominadas e dirigidas, tornado-se dominantes e dirigentes, mas caminhando historicamente na construção de uma realidade que não comporta a própria divisão de classes, isto é, um tipo de formação societária igualitária econômica, social, política e culturalmente, porque o que a caracteriza é a liberdade, auto-criação humana, e não a exploração de um grupo social sobre os demais, que resulta na alienação. Esse processo, objetivo e subjetivo,

[...] corresponde a diversos momentos da consciência política coletiva [...] O primeiro e mais elementar é o econômico-corporativo [...] [quando] sente-se a unidade homogênea do grupo profissional e o dever de organizá-la, mas não ainda a unidade do grupo social mais amplo. Um segundo momento é aquele em que se adquire a consciência da solidariedade de interesses entre todos os membros do grupo social, mas ainda no campo meramente econômico. Neste 
momento já se coloca a questão do Estado, mas apenas visando a alcançar uma igualdade político-jurídica com os grupos dominantes [...] Um terceiro momento é aquele em que se adquire a consciência de que os próprios interesses corporativos [...] superam o círculo corporativo, de grupo meramente econômico, e podem e devem tornarse os interesses de outros grupos subordinados. Esta é a fase mais abertamente política, que assinala a passagem nítida da estrutura para a esfera das superestruturas complexas; é a fase em que as ideologias germinadas anteriormente se transformam em "partido", entram em choque e lutam até que uma delas, ou uma combinação delas, tende a prevalecer, a se impor, a se irradiar em toda a área social, determinando, além da unicidade dos fins econômicos e políticos, também a unidade intelectual e moral [...] criando, assim, a hegemonia de um grupo social fundamental sobre uma série de grupos subordinados (GRAMSCI, 1980, p. 49- 50).

Desta feita, "[...] a conquista da hegemonia e o nascimento de um grupo social para a história estão ligados a uma dialética que atravessa essencialmente a auto-representação que aquele grupo possui de si mesmo [...]" (FINELLI, 2001, p. 02) sem desconsiderar que

[...] é no campo das experiências concretas, na interlocução crítica com a cultura e no embate com os projetos políticos existentes no movimento real da história que, para Gramsci, se chega progressivamente à compreensão de si mesmo, à elaboração de uma própria concepção de mundo, de uma teoria do conhecimento e à construção de métodos (SEMERARO, 2000, p. 01).

Dessa compreensão decorre que o processo de disputa pela hegemonia altera a situação material e, ao mesmo tempo, a consciência que os indivíduos das classes subalternas têm de si, seja como indivíduos, seja como grupo, seja como classe. De maneira que, no processo de construção de uma nova civilização, “[...] as classes instrumentais e subordinadas [...] - estarão caminhando para ter - um papel de direção na sociedade, como conjunto e não como indivíduos singulares" (GRAMSCI, 1995b, p. 149), e isso por que, na medida em que efetivam a luta social, os indivíduos vão

[...] passando por um processo educativo que os lev[a] a superar a condição de indivíduo, [e] efetivamente projeta[-os] na luta política, pois, conscientes e organizados coletivamente, buscarão a transformação das estruturas que produzem e reproduzem a desigualdade entre as classes sociais (MARTINS, 2000, p. 97). 
O processo de disputa pela hegemonia resulta, então, em interposições aos âmbitos subjetivo e intersubjetivo dos indivíduos ${ }^{12}$ das classes subalternas, isto é, produz "catarsis": “[...] transformação crítica do 'instinto', que é o grau mais baixo da consciência, em concepção proletária de mundo." (GRISONI; MAGGIORI, 1974, p. 219-220). Por meio deste processo, os indivíduos e grupos sociais das classes subalternas podem avançar de uma visão de mundo econômico-corporativa, que é meramente egoísta passional, passando pela solidariedade como grupo, até se alcançar a dimensão ético-política, por meio da qual se tem a unidade dos indivíduos que, como classe, não mais se contentam em reduzir os objetivos da ação que empreendem à mera conquista de direitos econômicos específicos, mas intencionam transformar toda a estrutura e a superestrutura social que produz e reproduz as relações sociais de tipo capitalista. Esta

[...] é a fase em que as ideologias germinadas anteriormente se transformam em "partido", entram em choque e lutam até que uma delas, ou uma combinação delas, tende a prevalecer, a se impor, a se irradiar em toda a área social, determinando, além da unicidade dos fins econômicos e políticos, também a unidade intelectual e moral [...] criando, assim, a hegemonia de um grupo social fundamental sobre uma série de grupos subordinados (GRAMSCI, 1980, p. 49-50).

Entre outras, duas observações devem ser destacadas dessa concepção que Gramsci apresenta de "catarsis". A primeira diz respeito à relação que tem com o pensamento marxiano: a concepção gramsciana de "catarsis" é muito próxima daquilo que Marx expressou com os conceitos "classe em si" e "classe para si" (MARX, 1990, p. 190) ${ }^{13}$ quando respondeu, por meio de seu texto intitulado A miséria da filosofia, a Proudhon e seu Filosofia da miséria; uma concepção próxima não no sentido de propriamente idêntica, mas um desenvolvimento em outro contexto, um continuidade histórica aprimorada pelas necessidades da luta pelo socialismo. A segunda observação é a que entende que a "catarsis", no seu mais elevado grau (a fase ético-político), deve ser resultado da práxis educativa que assevera o interesse e o compromisso com a transformação das estruturas e superestruturas capitalistas.

12 Para aprofundar a noção de indivíduo segundo o paradigma teórico-metodológico gramsciano, Ragazzini (2005).

13 Para Marx, "[...] a classe trabalhadora torna-se um objeto a serviço do capital quando se encontra restrita à sua condição econômica de classe. Mas quando ganha consciência de seu papel na totalidade da formação econômica e social capitalista, ou seja, quando adquire consciência de classe, ela se torna capaz de empreender a luta para superar a sua condição de classe, projetando-se na arena ético-política e epistemológica para transformar radicalmente as estruturas e as superestruturas sociais, assumindo-se como sujeito de um novo caminho para a história" (MARTINS, 2008, p. 84). 


\section{A EDUCAÇÃO COMO PRÁXIS PRODUTORA DE "CATARSIS"}

São inúmeras as teses acerca da origem do homem e dos motivos que o levaram ao seu atual patamar de desenvolvimento. Porém, é difícil encontrar entre elas as que negam que o homem como espécie transformou-se ao longo dos tempos, considerando-o no aspecto físico-biológico, econômico-social, ético-político e psicologicamente. $\mathrm{Na}$ verdade, é uma evidência histórica a transformação humana e, também, dos agrupamentos sociais no longo período compreendido entre a pré-história e os dias atuais, o que motiva a conclusão de que o homem e a humanidade não são mais os mesmos que já foram um dia.

Nessa discussão, é rotineira a tentativa de identificar as causas do processo de transformação e suas principais conseqüências à vida individual e coletiva. E é justamente assim que se conformam acalorados debates, nos quais se apresentam diferentes posições, inclusive as que negam que o desenvolvimento humano possa ser explicado pela lógica da causa-efeito, como é o caso das correntes que se afinam com a lógica dialética.

Nesse embate, apresentam-se teorias antropológicas e sociais que, ao avaliarem o processo de transformação humana, corroboram a idéia de que historicamente o homem aprendeu a ser outro, a pensar, a viver, a produzir e a sentir de maneiras diferentes, e tornando-se diferente, educou as gerações futuras de acordo com suas novas necessidades existenciais. Justamente aqui reside a tese de que a educação é um processo imanente ao histórico desenvolvimento humano, "Isto porque o homem não se faz homem naturalmente; ele não nasce sabendo ser homem, vale dizer, ele não nasce sabendo sentir, pensar, avaliar e agir. Para saber pensar e sentir; para saber querer, agir ou avaliar é preciso aprender, o que implica o trabalho educativo" (SAVIANI, 1992, p. 15).

Nos mais variados momentos históricos, as formações econômico-sociais, com suas características peculiares, projetaram um modelo ideal de homem a ser forjado, isto é, a ser constituído de acordo com as necessidades do momento vivido, de sua existência concreta. De acordo com esse ideal de homem, que corresponde ao seu tipo de vida social, forjaram-se variados modelos educativos, que apresentaram princípios, finalidades, métodos e linguagens específicas, configurando-se como parte integrante da superestrutura social que, em relação dialética com estrutura, colaboraram para forjar o homem à imagem e semelhança de sua vida concreta, de maneira que se pode dizer que "[...] o processo educativo [é aquele] pelo qual a humanidade elabora a si mesma, em todos os seus variados aspectos" (MANACORDA, 1999, p. 6). 
Assim, o ideal de homem a ser efetivado pelo processo educativo não é individualmente estabelecido e nem, muito menos, constitui-se como uma projeção idealizada de um grupo social isolado das relações sociais, das estruturas e superestruturas que a configuram. Historicamente, verifica-se que o modelo de homem que toda formação econômica e social projeta para si surge das complexas relações que se estabelecem na vida social, sobretudo considerando as necessidades que determinado modo de vida social adquire em um momento específico, que se apresenta ao homem e à humanidade como algo a ser saciado. Então, entre ideal de homem e modo de vida social estabelece-se uma relação dialética, uma inter-relação com a seguinte dinâmica: o modo de vida social exige um determinado tipo de homem, que deve ser formado pelo processo educativo; e o homem formado pelo processo educativo é quem efetiva o tipo de vida social em todas as suas dimensões.

O entendimento da relação entre processos educativos e modo de vida social dessa maneira dialética possibilita inferir que, primeiro, a educação não é completamente autônoma em relação à sociedade e, segundo, que justamente pela interdependência que mantém com outras instâncias e processos sociais, a educação, isoladamente, não tem a possibilidade de determinar os rumos do modo de vida social, ou melhor, transformar a sociedade em sua totalidade.

A primeira inferência indica que a autonomia da educação é sempre relativa às demais instâncias e processos sociais, políticos, econômicos, culturais, ideológicos, jurídicos, éticos etc. que caracterizam a totalidade de uma formação econômica e social. De maneira que a educação não é neutra, ou melhor, não é uma instância desvinculada da trama que caracteriza a vida concreta de uma formação econômica e social, pois esta totalidade contamina a educação ao manter com ela uma relação de interdependência, que faz com que "O concreto [seja] concreto porque é síntese de muitas determinações, isto é, unidade do diverso" (MARX, 1991, p. 16).

Essa compreensão desautoriza a assertiva de que a educação tem a capacidade de, isoladamente, transformar as relações sociais e determinar novos rumos para a totalidade da vida concreta, pois ela mantém com as demais instâncias e processos sociais uma relação de interdependência. Portanto, não é apenas a educação que determina o tipo de formação econômica e social, pois nesse processo incidem outros elementos que lhe são também determinantes.

Contudo, afirmar a autonomia relativa da educação em relação às demais instâncias e processos sociais e asseverar que ela não tem poder de isoladamente definir os rumos da vida social não implica em negar o seu papel relevante na construção de um modo de vida. E isso porque a educação colabora também 
PRÁXIS E "CATARSIS" COMO REFERÊNCIAS AVALIATIVAS DAS AÇÕES EDUCACIONAIS DAS ONG'S, DOS SINDICATOS E DOS PARTIDOS POLÍTICOS

para transformar as relações sociais vigentes em outras, e exerce esse seu precípuo desafio por meio da formação dos homens e mulheres segundo as necessidades da vida social, que se apresentam à educação como um ideal de homem a ser forjado.

Em outros termos, "[...] as mudanças das formas de produção da existência humana foram gerando historicamente novas formas de educação as quais, por sua vez, exerceram influxo sobre o processo de transformação do modo de produção correspondente" (SAVIANI, 1992, p. 10), do que resulta ser a educação socialmente determinada e, ao mesmo tempo, determinante da vida social. Por um lado, a educação é socialmente determinada porque não é um processo completamente transcendente às relações sociais, mas imanente ao processo histórico de produção e reprodução do modo de vida social: “[...] ela [é] social e determinada por condições sociais sob as quais você educa, por intervenção, direta ou indireta, da sociedade [...]" (MARX; ENGELS, 1996, p. 39). Por outro, a educação também é determinante da vida social porque forma o sujeito que age no mundo, que integra a vida social; um sujeito cujos conhecimentos, sentimentos, visão de mundo, idiossincrasias, habilidades e valores, que são referências para a sua ação, são aprendidos socialmente por diferentes meios e processos, ou seja, "[...] as circunstâncias têm de ser transformadas pelos homens e [...] o próprio educador tem de ser educado" (MARX, 1984, p. 108).

Ressalte-se que uma das formas pelas quais a educação exerce influxo sobre o processo de produção da existência, que é sua principal instância determinante, ocorre por meio da formação do homem como um ser que não se limita a simplesmente atender às necessidades de seu modo de vida social, como é o caso de formação de mão-de-obra para o mercado ${ }^{14}$, por exemplo, na atual fase de desenvolvimento do modo de produção capitalista. Se assim ocorresse, a educação seria sempre conservadora, porque atenderia única e exclusivamente às necessidades de uma formação econômica e social vigente ${ }^{15}$. Pelo contrário, o homem educado pode adquirir um grau de consciência suficiente para, com liberdade relativa (pois toda ação está limitada às condições objetivas e subjetivas vigentes), questionar as necessidades que lhe são impostas pelo modo de produção e articular processos sócio-políticos e culturais por meios dos quais pode transformar o próprio modo de vida vigente. E isso é possível porque a dinâmica da produção e reprodução da existência

14 A propósito, é por isso que "Uma reforma muito apreciada pelos burgueses é a educação [...]" (MARX; ENGELS, 1978, p. 73).

15 É exatamente essa visão sobre a educação que faz Saviani identificar um conjunto de teorias educacionais como reprodutivistas (SAVIANI, 1983). 
não se caracteriza como um processo social harmônico. Muito pelo contrário, a produção e reprodução da existência social são eivadas de contradições, sobretudo entre as forças que produzem a existência social (forças produtivas) e as relações sociais que se estabelecem a partir desse processo necessário à sobrevivência da humanidade. São essas contradições que possibilitam ao homem e a seus grupos sociais não apenas responderem às necessidades, mas também, com liberdade relativa, agirem para superar o modo de vida que gera as necessidades em um determinado momento histórico. Assim, a produção da consciência humana pela educação é um processo que repercute sobre o modo de produção da existência, o que pode fazer dela tanto um processo reprodutor da vida social como também algo que pode adquirir perfil transformador e mesmo revolucionário, considerando que em ambos os casos ela articula-se com outros processos sócio-históricos.

Dessa compreensão dialética sobre a relação entre educação e modo de vida social resulta a tese de que a educação é uma práxis, isto é, a educação é uma ação teórico-prática, que se manifesta na realidade concreta da vida social como processos de ensino-aprendizagem, por meio dos quais se procura efetivar o ideal de homem segundo as necessidades de uma determinada formação econômica e social ou, valendo-se da liberdade humana, questiona o ideal vigente e lhe propõe outros, mobilizando as vontades e as convicções de sujeitos individuais e grupos sociais até transformar suas ações em efetiva "[...] força material quando se apodera das massas [de maneira que] [...] a emancipação teórica possui uma importância característica prática" (MARX, 2002, p. 53).

De uma maneira ou de outra, isto é, seja atendendo as necessidades, e assim assumindo-se como conservadora (no sentido de atender às demandas do modo de vida vigente), seja usufruindo da relativa liberdade conquistada, e assumindo-se como transformadora ou, mais radicalmente, revolucionária (porque contrária à tendência demandada pelo modo de vida), a educação é parte integrante da totalidade complexa e contraditória que é a vida social. E, como tal, caracteriza-se não apenas como um processo que lida com elementos imateriais, como por exemplo, conhecimentos, valores, linguagens etc., mas também com elementos e sistemas materiais, como os aparatos e processos propriamente econômicos relacionados ao modo de produção, que determinam também a educação e é por ela determinado numa relação dialética.

Se historicamente o homem se diferenciou dos demais animais porque superou os desafios que a natureza lhe impôs pelo trabalho, nas suas diferentes modalidades, ao modificar a natureza segundo suas necessidades e 
vontades transformadas em força material, o homem também se transformou. Isto é, historicamente educou-se, aprendeu a ser outro diferente do que era para atender às necessidades do tipo de existência e mesmo suas convicções pessoais e sociais; e ao educar-se produziu outras necessidades existenciais e capacidades ${ }^{16}$ com potencial de desenvolver novas forças produtivas, que incidiram sobre o processo educativo dialeticamente e forjaram diferentes modos sociais de vida, cada qual com suas contradições e seus respectivos processos educativos, desde os menos sistemáticos e formais, como a educação prática primitiva, até os mais sistemáticos e formais sistemas educativos escolares modernos (PONCE, 2000), e mesmos os processos educacionais não escolares atuais. (MARTINS, 2007).

"Na realidade, toda geração educa a nova geração, isto é, forma-a; [...] a fim de [...] criar o homem 'atual' à sua época” (GRAMSCI, 1995b, p. 142). Nessa perspectiva, a educação consiste em um processo histórico de formação global do homem e da humanidade, por diferentes meios, e em relação dialética com as dimensões econômicas, sociais, políticas e culturais de uma determinada formação econômica e social, porquanto por educação se entende "[...] o ato de produzir, direta e intencionalmente, em cada indivíduo singular, a humanidade que é produzida histórica e coletivamente pelo conjunto dos homens." (SAVIANI, 1992, p. 21).

Ocorre que ao produzir a história da humanidade pela práxis, incluindo aquelas que se efetivam por meio de processos de ensino-aprendizagem, o homem educa-se, ou melhor, apresenta-se como um ser sujeito a transformações em seu ser e em sua consciência, em sua representação do mundo ao redor e em sua própria auto-representação, isto é, produz "catarsis". Todavia, as "catarsis" inerentes ao desenvolvimento dos processos educativos podem adquirir perfil reprodutor ou conservador da realidade vigente em uma formação econômica e social. De maneira que, se se pretende avaliar os resultados dos processos educativos desenvolvidos pelos agentes sociais, especificamente dos que se assumem como transformadores da realidade vivida, como é o caso de muitas ONG's, sindicatos e partidos políticos, deve-se considerar a necessidade de identificar as "catarsis" que promovem.

16 "O primeiro ato histórico é, portanto, a produção dos meios para a satisfação destas necessidades, a produção da própria vida material, e a verdade é que este é um ato histórico, uma condição fundamental de toda a História, que ainda hoje, tal como há milhares de anos, tem de ser realizado dia a dia, hora a hora, para ao menos manter os homens vivos [...] a própria primeira necessidade satisfeita [manter a sobrevivência], a ação da satisfação e o instrumento já adquirido da satisfação, conduz a novas necessidades - e esta produção de novas necessidades é o primeiro ato histórico.” (MARX; ENGELS, 1984, p. 31-32). 


\section{APONTAMENTOS CONCLUSIVOS: PRÁXIS E "CATARSIS" COMO REFERÊNCIAS AVALIATIVAS DAS AÇÕES EDUCACIONAIS NÃO-ESCOLARES}

Pelo exposto, cuja orientação foi a do postulado marxiano e marxista gramsciano da unidade dialética entre ser e pensar, a práxis foi definida como ação teórico-prática do homem que transforma historicamente a realidade segundo suas necessidades de sobrevivência e as exigências de sua existência, delimitadas pelo contexto societário vivido. Assim entendida, a práxis impacta o âmbito material e i-material das formações econômicas e sociais, o que torna possível tomar os resultados que ela provoca no nível concreto da realidade e no âmbito subjetivo e intersubjetivo como elementos avaliativos das ações educacionais.

Muito embora o resultado da educação dependa, em larga medida, do processo pelo qual ela é produzida - como é o caso dos métodos empregados, por exemplo -, interessa particularmente nesta parte final do presente texto apresentar referências para tomar apenas um de seus resultados como objeto de avaliação, qual seja a "catarsis" provocada pela práxis educativa, e a práxis desenvolvida especificamente por agentes educacionais não escolares: as ONG's, os sindicatos e os partidos políticos. Eis o intento das brevíssimas linhas conclusivas que se seguem, nas quais se procura enfrentar o desafio axiológico e heurístico de delinear parâmetros para a avaliação das ações educacionais a partir dos conceitos que Marx, Gramsci e Vázquez têm de práxis, e que o revolucionário italiano da Sardenha, Gramsci, tem de "catarsis".

Importa considerar inicialmente que toda práxis educativa, isto é, toda ação teórico-prática que se efetiva como processo de ensino-aprendizagem, produz alterações nos sujeitos. Todo e qualquer sujeito que vive, educa-se, isto é, ensina e aprende, e ao ser educado é modificado de alguma forma, sobretudo se considerado o âmbito de sua subjetividade. Por conseguinte, alegar que determinada práxis educativa transforma sujeitos não é caracterização distintiva entre elas, porquanto todas as práxis educativas alteram os sujeitos em alguma medida.

Contudo, as referências às formulações de Vázquez possibilitam fazer uma distinção entre as práxis educativas das ONG's, dos sindicatos e dos partidos políticos, considerando o grau de consciência que os sujeitos que a desenvolvem têm sobre sua ação (e a assim elas poderão ser identificadas como criativa, reiterativa ou mimética), e também sobre os resultados alcançados, que poderão ser os que foram previamente planejados (no caso da práxis reflexiva) ou os que foram "espontaneamente" atingidos (no caso da práxis espontânea). Seja com um tipo de práxis livre e criativa ou mesmo seguindo padrões e modelos 
PRÁXIS E "CATARSIS" COMO REFERÊNCIAS AVALIATIVAS DAS AÇÕES EDUCACIONAIS DAS ONG'S, DOS SINDICATOS E DOS PARTIDOS POLÍTICOS

estabelecidos, as ações educativas das ONG's, dos sindicatos e dos partidos políticos provocam alterações nos sujeitos, isto é, transforma-os, e tal transformação poderá ser a previamente planejada ou alcançada "espontaneamente".

Essas distinções, que podem ser aplicadas ao processo de identificação e avaliação das práxis educativas efetivadas pelas ONG's, pelos sindicatos e pelos partidos políticos, seguindo os critérios vazqueanos, são bastante interessantes, mas não tão significativas se o interesse for o de identificar e avaliar os impactos que causam na totalidade da realidade vivida. Neste caso, será preciso tomar como objeto de análise a "catarsis" provocada pela práxis educativa, que pode ser um importante critério distintivo entre as mais variadas práxis.

Ao tomar como referência o conceito gramsciano de "catarsis", pode-se diferenciar as práxis educativas desenvolvidas pelas ONG's, sindicatos e partidos políticos a partir do impacto que elas causam na consciência dos educandos e na sua conseqüente ação em uma formação econômica e social específica. Daí o fato de a "catarsis" poder ser tomada como critério avaliativo das práxis educativas, sobretudo daqueles que discursivamente alegam educar para transformar os sujeitos e a realidade, como é caso de grande parte das ONG's, dos sindicatos e mesmo dos partidos políticos, sobretudo dos que se apresentam no espectro político-partidário posicionados no que se convencionou chamar de esquerda.

A práxis educativa desenvolvida por esses sujeitos educacionais adquire perfil conservador da totalidade social quando promove um tipo de "catarsis" que mantém a consciência dos educandos no nível "econômico corporativo", da qual resultam ações que até transformam os indivíduos, tornando-os aptos a, com sua ação, promoverem mudanças na vida pessoal e no ambiente comunitário (o micro-cosmo por ele vivido), mas não conseguem impactar as estruturas e superestruturas que caracterizam a vida social como um todo, pois a ação resultante da consciência "econômico corporativa" é bastante limitada e acaba sendo incorporada na dinâmica societária e, por conseguinte, na reprodução do modo de vida vigente.

Essa é a característica da práxis educativa desenvolvida por muitas ONG's atualmente, mormente pelas que se identificam como pertencentes ao "terceiro setor", que se auto-declara "[...] como elemento que promove a solidariedade social para além do Estado [primeiro setor] e do mercado [segundo setor] [...] apresentando-se como um 'novo' setor social" (MARTINS; GROPPO, 2010, p. 123) formado por organizações sociais institucionalizadas ou não, como ONG's - Organizações Não-Governamentais -, fundações, institutos, OS's Organizações Sociais -, OSIP's - Organizações Sociais de Interesse Públicos - e outras denominações que possam adquirir na linguagem corrente ou que a 
legislação nacional vigente possa lhes atribuir. A práxis educativa desenvolvidas por esses agentes sociais

Revela que o compromisso do 'terceiro setor' não é propriamente com projetos globais de libertação das condições que produzem carências de toda espécie e as vergonhosas desigualdades sociais; sobre essa questão prefere assumir a 'neutralidade', o silêncio, a indiferença [...] Esconde, todavia, que os resultados de sua ação sempre fragmentária não impactam decisivamente o status quo, tornando-se, então, dele colaboradora $[. .$.$] (idem).$

Neste sentido, e considerando a "catarsis" dela resultante, pode-se identificar esse tipo de práxis como uma

[...] "práxis comunitária" [isto é, um tipo de ação que] tem um limitado alcance histórico, ou melhor, não há nela grandes preocupações em conhecer e nem em transformar globalmente a realidade, mas principalmente promover ajustes parciais, sem afetar a dinâmica global do modo de vida. Ao invés de redirecionar as relações societárias, as alterações minimalistas que a "práxis comunitária" nela promove colabora com a sua revitalização e reprodução, o que é bom para as classes dominantes e dirigentes, mas ruim para quem sofre as conseqüências da nefasta lógica da exclusão, da coisificação e do fetichismo próprios do sistema de vida sob a forma do capitalismo flexível (MARTINS, 2007, p. 115).

A práxis educativa, seja a dos agentes auto-intitulados como pertencentes ao "terceiro setor", seja a dos sindicatos e partidos políticos, só começará se tornar realmente transformadora da totalidade da vida social, o que exige dos sujeitos plena consciência de sua ação, na medida em que provocar um tipo específico de "catarsis" que avance da consciência econômico-corporativa para a de solidariedade de grupo, e desta até atingir o seu estágio mais desenvolvido, que é aquele em que ela se configura como eminentemente ético-política. Por meio dela, os sujeitos têm plena consciência de si e da realidade, e podem mover-se no âmbito do ser e do pensar de uma situação de "classe em si" para a de "classe para si", conforme Marx expôs.

Assim, a práxis educativa das ONG's, dos sindicatos e dos partidos políticos só será transformadora da totalidade da vida social se, e somente se, provocar nos indivíduos uma elevação de sua consciência e transformação de sua ação, de forma a promover a superação de sua visão corporativa como indivíduo identificado pela situação econômica e o projetá-lo à identificação com outros 
indivíduos e grupos explorados pela dinâmica econômica e subordinados éticopolítica e culturalmente aos interesses da classe hegemônica, do que poderá resultar uma ação eminentemente política com vistas a transformar globalmente as estruturas e as superestruturas que configuram o tipo de formação econômica e social vigente. Com efeito, este tipo de práxis do indivíduo poderá ser qualificada como "práxis social", assim entendida:

[...] "práxis social" é profundamente diferente do "agir comunitário" (GOHN, 1999, p. 86) empreendido atualmente, mormente pelo que denominamos de "terceiro setor". Aliás, as diferenças entre a "práxis social" até então desenvolvida pelas classes subalternas e seus intelectuais orgânicos e a "práxis comunitária", hoje posta em prática por algumas organizações sociais, são de tal ordem que entre elas se configura uma verdadeira oposição. Enquanto a "práxis social" buscava a mobilização das massas pela ação politizada e ideologizada, articulada por instrumentos organicamente vinculados entre si (como os partidos, os sindicatos e até mesmo mediante organizações internacionais dos trabalhadores, como é o caso das "Internacionais"), que indicavam o engajamento permanente e a perspectiva estratégica de transformação global do modo de vida, a "práxis comunitária" é focalizada, despolitizada, e articulada por instrumentos de mobilização cujo engajamento é eventual e de perspectiva não estratégica, além de afirmar-se como neutra ideologicamente. Um exemplo elucidativo da oposição anunciada entre "práxis social" e "práxis comunitária" pode ser conferido ao se observar os sujeitos de cada uma delas, que respectivamente são o militante e o voluntário. O primeiro é o paradigma da ação social de perfil moderno, cujo engajamento e luta no processo de transformação social é princípio e finalidade de vida, enquanto que o voluntário, como o modelo de ação do "terceiro setor", se engaja momentaneamente, sobretudo em campanhas específicas para tratar de problemas particulares, que não comprometem a sua vida e nem, muito menos, implica em riscos para o sistema social vigente, que o incorpora dinâmica reprodutiva (MARTINS, 2007, p. 117).

Dessa maneira, pode-se qualificar a práxis desenvolvidas pelas ONG's, pelos sindicatos e pelos partidos políticos a partir do grau de consciência que os sujeitos que deles participam como indivíduos e como grupos sociais têm da ação e os resultados alcançados, mas a principal distinção da práxis educativa ocorre se avaliada a "catarsis" por ela promovida: ela avançará de uma "práxis comunitária", com limitado alcance transformador da globalidade da realidade vivida, para a "práxis social", quando provocar impactos em toda a estrutura e superestrutura social por promover um tipo de "catarsis" que eleve a consciência e a ação dos sujeitos do nível econômico-corporativo para o ético-político. 
Uma ressalva, por fim, deve ser feita, qual seja a de que é importante não generalizar o alcance desses conceitos de "práxis comunitária" e "práxis social" aos exemplos citados por dois motivos básicos: primeiro porque há organizações que, dependendo da compreensão que se tem de "terceiro setor", poderiam ser enquadradas nele, mas que desenvolvem práxis qualificadas como "práxis social", como é o caso do MST - Movimento dos Trabalhadores Rurais Sem Terra; e, segundo, por que há agentes sociais na realidade atual com discursos que asseveram a transformação global do modo de vida social, como muitos sindicatos e partidos políticos, mas que concretamente desenvolvem um tipo de práxis educativa que nada mais produz senão "catarsis" que se integram na dinâmica societária como elementos de conservação e, portanto, devem ser identificadas como "práxis comunitária".

\section{REFERÊNCIAS}

ABBAGNANO, Nicola. Dicionário de filosofia. Trad. de Alfredo Bosi e revisão de Ivone Castilho Benedetti. São Paulo: Martins, Fontes, 2000.

BERTI, Enrido. As razões de Aristóteles. Trad. de Dion Davi Macedo. São Paulo: Loyola, 1998. (Coleção Leituras Filosóficas)

BOTTOMORE, Tom. Dicionário do pensamento marxista. Trad. de Waltensir Dutra. Rio de Janeiro: Jorge Zahar, 1988.

FINELLI, Roberto. As contradições da subjetividade: Americanismo e fordismo em Antonio Gramsci. Disponível em: <http//www.artnet.com.br>. Acesso em: 18.dez. 2001.

GOHN, Maria da Glória. Educação não-formal e cultura política:

impactos sobre o associativismo do terceiro setor. São Paulo, Cortez, 1999. (Coleção Questões de nossa época; v. 71)

GRAMSCI, Antonio. Maquiavel, a política e o Estado moderno. 4. ed. Trad. de Luiz Mário Gazzaneo. Rio de Janeiro: Civilização Brasileira, 1980.

Concepção dialética da história. 10. ed. Trad. de Carlos Nelson Coutinho. Rio de Janeiro: Civilização Brasileira, 1995a.

. Os intelectuais e a organização da cultura. 9. ed. Trad. de Carlos Nelson Coutinho. Rio de Janeiro: Civilização Brasileira, 1995 b. 
PRÁXIS E "CATARSIS" COMO REFERÊNCIAS AVALIATIVAS DAS AÇÕES EDUCACIONAIS DAS ONG'S, DOS SINDICATOS E DOS PARTIDOS POLÍTICOS

GRISONI, Dominique; MAGGIORI, Robert. Ler Gramsci. Prefácio de François Châtelet e Maria Antonieta Maccciochi. Lisboa: Inciativas Editoriais, 1974.

KOSIK, Karel. A dialética do concreto. 2. ed. Trad. de Célia Neves e Alderico Toríbio. Rio de Janeiro: Paz e Terra, 1976.

LEFEBVRE, Henri. A "práxis": a relação social como processo. In: FORACCHI, Marialice Mencarini; MARTINS, José de Souza. Sociologia e sociedade - leituras de introdução à Sociologia. Rio de Janeiro: LTC, 2002. p. 147-159.

\section{LÊNIN, Vladimir Ilitch. As três fontes e as três partes constitutivas do} marxismo. São Paulo: Global Editora, 1985. (Coleção Bases, v. 9)

MANACORDA, Mario Alighiero. História da educação: da antiguidade aos nossos dias. Trad. de Gaetano Lo Monaco. 7. ed. São Paulo: Cortez, 1999.

MARTINS, Marcos Francisco. Ensino técnico e globalização: cidadania ou submissão? São Paulo: Autores Associados, 2000. (Coleção Polêmicas do Nosso Tempo)

. Pedagogia do engajamento: considerações sobre a desumanização e as possibilidades de sua superação. Revista Práxis Educativa, Ponta Grossa, v. 3, n. 1, p. 55-66, jan./jun. 2008.

. Educação sócio-comunitária em construção. Revista Histedbr Online, Campinas, n. 28, p. 106-130, dez. 2007, Disponível em: <http://www. histedbr.fae.unicamp.br/revista/edicoes/28/art08_28.pdf $>$. Acesso em: 02 set. 2010 .

; GROPPO, Luís Antonio. Sociedade civil e educação: fundamentos e tramas. Campinas: Autores Associados, 2010. (Coleção Educação Contemporânea)

MARX, Karl. Teses sobre Feuerbach. In: MARX, Karl; ENGELS, Friedrich. A ideologia alemã (Feuerbach). Trad. de José Carlos Bruni e Marco Aurélio Nogueira. 5. ed. São Paulo: Hucitec, 1986.

. Para a crítica da economia política - Prefácio. Trad. de José Carlos Bruni, José Arthur Giannotti, Edgard Malagodi e Walter Rehfeld. 5. ed. São Paulo, Abril Cultural, 1991. (Os Pensadores, v. 12). 
. O capital: crítica da economia política. Trad. de Reginaldo Sant'Ana. 17. ed. Rio de Janeiro, Civilização Brasileira, 1999. v. I. MARX, Karl; ENGELS, Friedrich. Crítica da educação e do ensino. Trad. de Ana Maria Rabaça. Lisboa: Moraes, 1978.

A ideologia alemã $-1^{\circ}$ capítulo seguido das Teses sobre Feuerbach. São Paulo: Moraes, 1984.

Miséria da filosofia. Trad. de Luís M. Santos. São Paulo: Mandacaru e Estampa, 1990.

. Para a crítica da economia política - Prefácio. Trad. de José Carlos Bruni, José Arthur Giannotti, Edgard Malagodi e Walter Rehfeld. 5. ed. São Paulo: Abril Cultural, 1991. (Coleção Os Pensadores; v. 12).

. O manifesto comunista. Trad. de Maria Lucia Como. Rio de Janeiro: Paz e Terra, 1996. (Coleção leitura)

. Manuscritos econômicos e filosóficos. Trad. de Alex Marins. São Paulo: Martin Claret, 2002.

PONCE, Aníbal. Educação e luta de classes. Trad. de José Severo de Camargo Pereira. 17. ed. São Paulo: Cortez, 2000.

PORTELLI, Hugues. Gramsci e o bloco histórico. 5. ed. Trad. de Angelina Peçanha. São Paulo: Paz e Terra, 1990.

SAVIANI, Dermeval. Escola e democracia. Campinas: Autores Associados; Cortez, 1983. (Coleção Polêmicas do Nosso Tempo, v. 5)

. Pedagogia histórico-crítica: primeiras aproximações. 3. ed. São Paulo: Cortez; Autores Associados, 1992. (Coleção polêmicas do nosso tempo, v. 40).

RAGAZZINI, Dario. Teoria da personalidade na sociedade de massa: a contribuição de Gramsci. Trad. de Maria de Lourdes Menon. Campinas: Autores Associados, 2005.

SEMERARO, Giovanni. Intelectuais “orgânicos” em tempo de pós-modernidade. Cadernos CEDES, Campinas, v. 26, n. 70, p. 373-391, set./dez.2006, Disponível em: $<$ http://www.scielo.br/scielo.php?pid=S0101-3262200 6000300006\&script=sci_arttext\&tlng=en\%5D >. Acesso em: 12 fev. 2009. VÁZQUEZ, Adolfo Sánches. Filosofia da praxis. Trad. de Luiz Fernando Cardoso. 2. ed. Rio de Janeiro, Paz e Terra, 1977. 